\title{
A novel through-the-scope twin endoclip for a large mucosal closure in a live pig model
}

A novel through-the-scope twin endoclip (TTS-TC) has been developed by our team. The TTS-TC can be delivered directly through an endoscope working channel of $3.2 \mathrm{~mm}$ in diameter and contributes to the closure of large mucosal wounds.

A living pig (Feed Research Institute, Guangzhou City, China) weighing $30.5 \mathrm{~kg}$ was used to conduct the experiment in vivo. A QF-260] gastroscope (Olympus, Tokyo, Japan) was used. TTS-TC was used to reduce the size of the mucosal wound after endoscopic submucosal dissection (ESD) ( $>$ Video 1 ).

The operation steps were as follows. First, the TTS-TC was delivered to the site of the ESD wound through the endoscope working channel ( Fig.1a). The clip on one side of TTS-TC was opened by operating the handle of the TTS-TC system, followed by tight clamping of mucosal tissue on one side of the wound

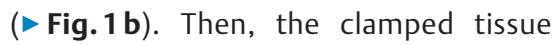
was pulled toward the opposite side of the wound ( $\nabla \mathbf{F i g . 1 c}$ ), and the second clip on the TTS-TC was opened to clamp the mucosal tissue on this side of wound ( $\vee$ Fig.1d). After the two sides of the wound had been clamped together, the TTS-TC was released and the wound was closed ( $\triangleright$ Fig.1e). Using this TTS-TC technique, the large wound on the anterior wall of the greater curvature of the stomach was successfully turned into two smaller wounds. After using a TTSTC, the wound size decreased, and TTSTC or traditional through-the-scope clips (TTSC) could subsequently be used to close the wound conveniently.

The size of the wound in the current case was $3.4 \times 3.3 \mathrm{~cm}$. The currently available through-the-scope clips can only close a wound of $<2 \mathrm{~cm}[1]$, and the over-thescope-clip requires installation on the outside of the endoscope tip and sometimes the endoscope may need to be reinserted [2,3]. The TTS-TC device seems to be simple and rapid in operation, and can be used to close a large mucosal wound.
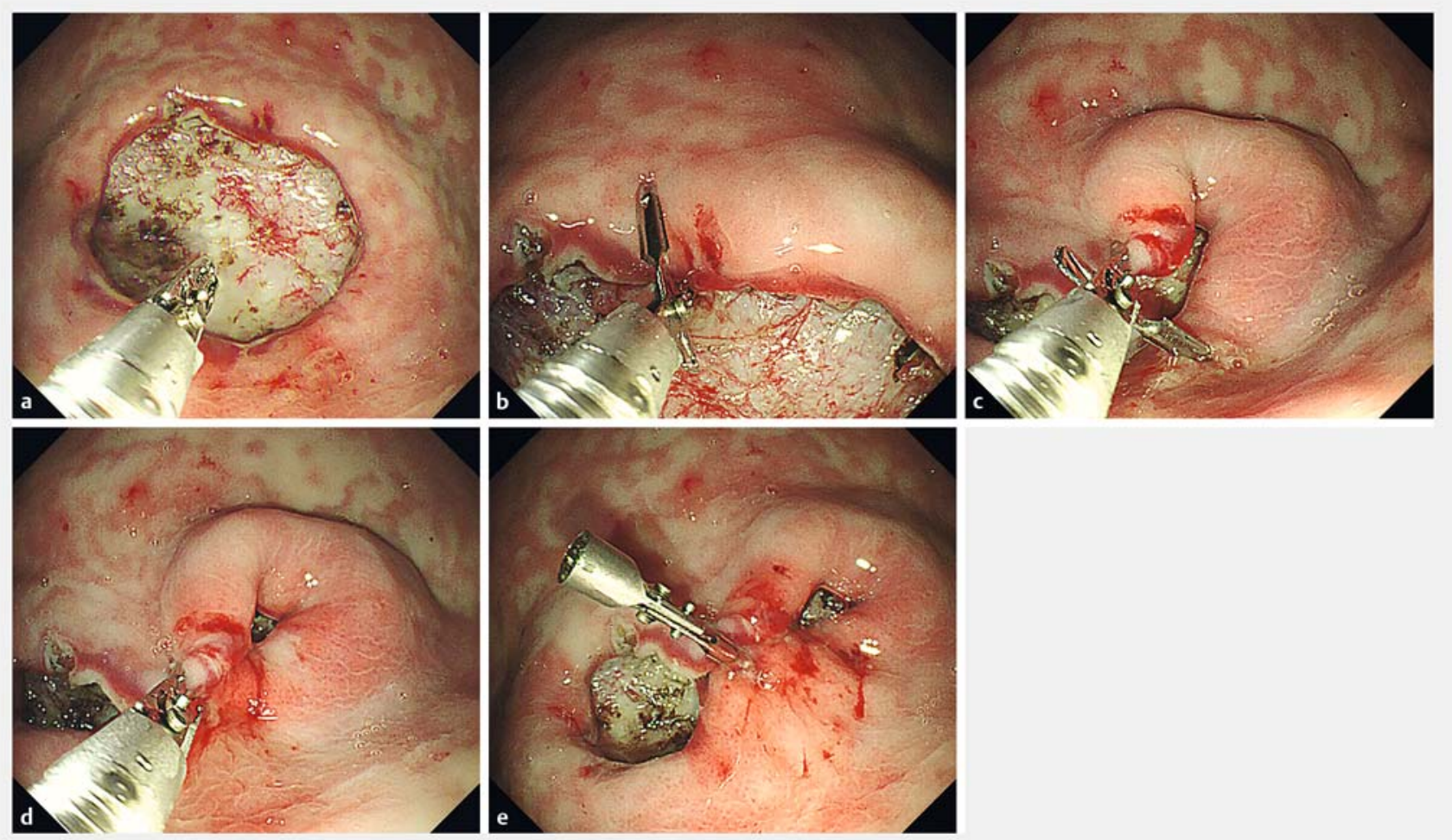

- Fig. 1 A large wound after endoscopic submucosal dissection was successfully turned into two smaller wounds by the use of the through-thescope twin endoclip (TTS-TC). a The TTS-TC was delivered to the site of the wound through the endoscope working channel. b The mucosal tissue on one side of the wound was clamped using the TTS-TC. c The clamped tissue was then pulled across to the opposite side of the wound, and the second TTS-TC was used to clamp the tissue on this side. $\mathbf{d}$, e The mucosae on both sides of the wound were clamped together; the headend part of the TTS-TC was then released. 


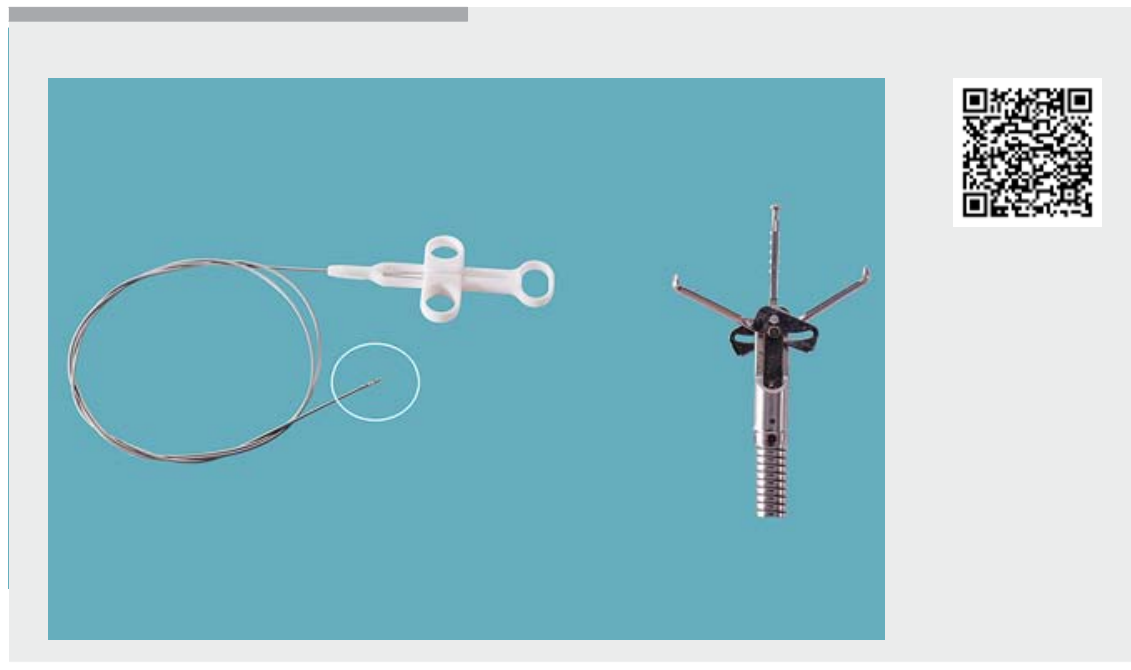

$\checkmark$ Video 1 A novel through-the-scope twin endoclip for closure of a large mucosal wound in a live pig model.
Endoscopy_UCTN_Code_TTT_1AQ_2AJ and Endoscopy_UCTN_Code_TTT_1AO_2AD

\section{Competing interests}

None

\section{The authors}

\section{Qiang Zhang, Zhen Wang, Yang Bai}

Guangdong Provincial Key Laboratory of Gastroenterology, Department of

Gastroenterology, Nanfang Hospital, Southern Medical University, Guangzhou, China

\section{Corresponding author}

Qiang Zhang, MD

Guangdong Provincial Key Laboratory of Gastroenterology, Department of Gastroenterology, Nanfang Hospital, Southern Medical University, Guangzhou, China

Fax: +86-20-87280770

4024313@qq.com
[1] Hayashi I, Yonezawa TM, Kuwabara T et al. The study on staunch clip for the treatment by endoscopy. Gastrointest Endosc 1975; 17: $92-101$

[2] Singhal S, Changela K, Papafragkakis $\mathrm{H}$ et al. Over the scope clip: technique and expanding clinical applications. J Clin Gastroenterol 2013; 47: 749-756

[3] Banerjee S, Barth BA, Bhat YM et al. Endoscopic closure devices. Gastrointest Endosc 2012; 76: $244-251$

\section{Bibliography}

DOI https://doi.org/10.1055/a-0948-5252

Published online: 1.7.2019

Endoscopy 2019; 51: E372-E373

(c) Georg Thieme Verlag KG

Stuttgart · New York

ISSN 0013-726X

\section{ENDOSCOPY E-VIDEOS \\ https://eref.thieme.de/e-videos}

回的回 Endoscopy E-Videos is a free access online section, reporting 回: on interesting cases and new techniques in gastroenterological endoscopy. All papers include a high quality video and all contributions are freely accessible online.

This section has its own submission website at https://mc.manuscriptcentral.com/e-videos 